Research Article

\title{
Drug utilization study in postoperative patients in obstetrics and gynaecology ward of tertiary care hospital
}

\author{
Rajeshwari*, Nagabushan $H$.
}

\author{
Department of Pharmacology, \\ Mandya institute of Medical \\ sciences, Mandya, Karnataka, \\ India \\ Received: 06 January 2016 \\ Accepted: 03 February 2016 \\ *Correspondence to: \\ Dr. Rajeshwari, \\ Email: rajeshwarineela6@ \\ gmail.com \\ Copyright: (C) the author(s), \\ publisher and licensee Medip \\ Academy. This is an open- \\ access article distributed under \\ the terms of the Creative \\ Commons Attribution Non- \\ Commercial License, which \\ permits unrestricted non- \\ commercial use, distribution, \\ and reproduction in any \\ medium, provided the original \\ work is properly cited.
}

\begin{abstract}
Background: A growing number of pharmaceutical products are available in the world market and there has been an increase both in the consumption of the drugs and in expenditure on them. The aim of the study was to analyse drug usage in post-operative patients in obstetrics and gynaecological ward and to assess the prescribing indicators (WHO: Core Drug Use Indicators).

Methods: A prospective observational study was conducted over a period of six months, after getting approval from Institutional Ethics committee. A specially designed proforma was used to collect the data of post-operative patients in Obstetrics and Gynaecological ward of a tertiary care hospital. The data was analysed using descriptive analysis with the help of SPSS software.

Results: A total of 582 cases were analysed during the study. Out of 582 patients, $559(96 \%)$ were prescribed with parenteral cefotaxime and metronidazole. Post-operative pain was managed with tramadol (96\%). All patients were prescribed with an antibacterial agent and analgesic (100\%). The percentage of encounters with an injection prescribed was $100 \%$ in our study. Out of 19 different drugs prescribed, 16 (84.21\%) were from the Essential Medicines WHO Model List (2015) and 10 (52.63\%) were prescribed by their generic name.

Conclusions: The present study provides valuable insight about the overall pattern of drug used in postoperative patients. The study is useful in decreasing the irrational prescription, which helps to decrease the morbidity and health care burden in the society.
\end{abstract}

Keywords: Drug utilization, Post-operative, Obstetrics and gynaecology

\section{INTRODUCTION}

WHO defines drug utilization as "the marketing, distribution, prescription and use of drug in a society with special emphasis on resulting medical, social and economic consequences."1

The principal aim of drug utilization research is to facilitate rational use of drugs in the population. A growing number of pharmaceutical products are available in the world market and there has been an increase both in the consumption of the drugs and in expenditure on them. ${ }^{2}$ Although rational use of drugs is quite a usual practice but sometimes certain factors may cause irrational practice. Monitoring of prescriptions and drug utilization studies could identify the associated problems and provide feedback to prescribers. ${ }^{3}$

In most hospitals and clinics, conventional antibacterial therapy is given usually for 7-10 days to postnatal patients with episiotomy as well as post-surgical patients. It increases the cost for the patient, increases workload on hospital staff and results in emergence of antimicrobial resistance. $^{4}$

Surgical site infections are common complication of obstetric and gynaecological surgeries; up to $10 \%$ of gynaecological patients undergoing an operative procedure will develop a surgical site infection. ${ }^{5}$ The principles of surgical prophylaxis have been established over years. Selection of antibacterial agent for prophylaxis should be based on its activity against anticipated bacteria at the specific surgical site. ${ }^{6}$ Properly timed accurate dose of preoperative antibacterial agent reduces the incidence of surgical site infection. ${ }^{7}$

Developing countries have limited funds available for healthcare and drugs and it becomes very important to prescribe drug rationally so that the available funds can be utilized optimally. ${ }^{8}$ 
Postoperative utilization of drugs is very much marked. Drugs are prescribed for the purpose of analgesia, prevention of infection, nausea and vomiting, to maintain the haemodynamic status. ${ }^{9}$ Since there are very few studies which describe the utilization of drugs postoperatively, this study was conducted to provide the drug utilization pattern in postoperative wards.

\section{METHODS}

The study was conducted in department of Obstetrics and Gynaecology of a tertiary care teaching hospital. Case records of the patients admitted to Obstetrics and Gynaecological post-operative ward were collected after obtaining the approval of Institutional Ethics committee.

Details of each case were recorded in separate predesigned and pretested proforma.

As per selection criteria, total 582 patients were enrolled in the study and demographic data, diagnosis, on-going treatment were recorded and analysed.

\section{Inclusion criteria}

- The patients who underwent major operative procedure in the age group of 18 to 70 years were recruited in this study.

\section{Exclusion criteria}

- Patient who were not consenting for the study

- Patient discharged against medical advice

- Patient who were referred to higher centre were excluded from the study.

\section{Data analysis}

Rationality of prescription was analysed by comparing with following WHO prescribing indicators -

- Average number of drugs per encounter.

- Percentage of drugs prescribed by generic name.

- Percentage of encounters with an antibiotic prescribed.

- Percentage of encounters with an injection prescribed.

- Percentage of drugs prescribed from essential drugs list or formulary.

Data were analysed using descriptive statistics.

\section{RESULTS}

In the present study, total numbers of patients were 582 . The patients had undergone different types of surgeries during the study. Lower segment caesarean section (LSCS) was the most common surgery (546 patients), followed by hysterectomy (36 patients). Among the
Lower segment caesarean section, most common performed surgery was Emergency LSCS, followed by Elective LSCS. Different indication for lower segment caesarean section is shown in Figure 1.

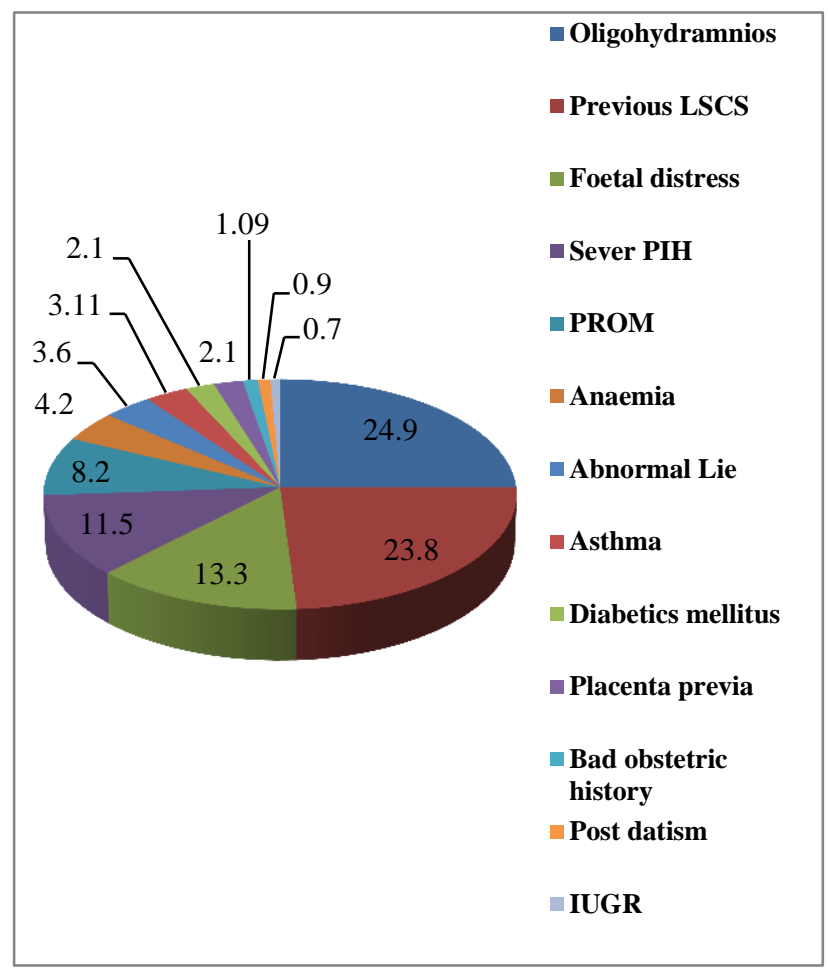

Figure 1: Indications for LSCS.

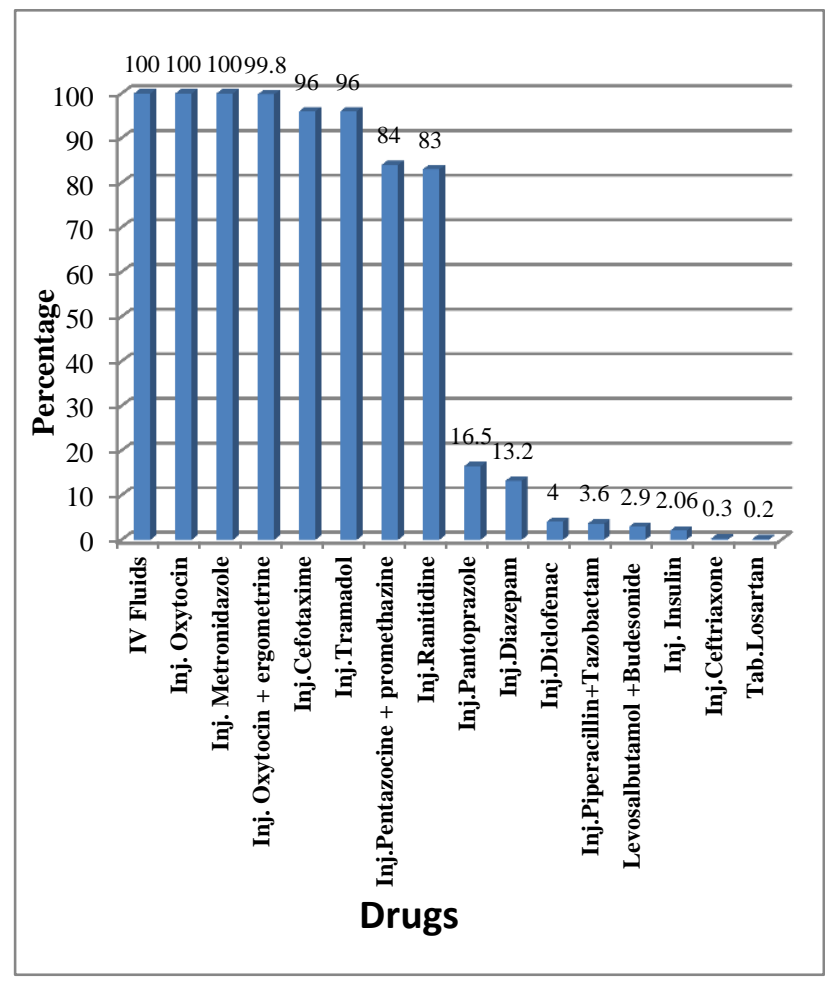

Figure 2: Percentage of most commonly used drugs. 
Table 1: Percentage of antibiotic usage ( $n=582)$.

\begin{tabular}{|llcc|}
\hline Antibiotic & $\begin{array}{l}\text { Group of } \\
\text { antibiotic }\end{array}$ & Frequency & $\%$ \\
\hline Inj. Cefotaxime & Cephalosporin & 559 & 96 \\
\hline Inj. Metronidazole & Antiamoebic & 582 & 100 \\
\hline $\begin{array}{l}\text { Inj. Pipercillin \& } \\
\text { Tazobactam }\end{array}$ & Beta-Lactam & 21 & 3.6 \\
\hline Inj. Ceftriaxone & Cephalosporin & 2 & 0.3 \\
\hline
\end{tabular}

Most commonly prescribed drugs in decreasing frequency are shown in Figure 2. The average number of drugs prescribed per patient was 9.8 .

In our study, total patients with an antimicrobials prescribed were 582 and percentage of patients with an antibacterial prescribed was $100 \%$ (Table 1).

Most commonly used antibacterial combination was metronidazole (582) along with cefotaxime (559) and pipercillin and tazobactam (21). An injection was prescribed in all the 582 patients either as an injectable antibacterial agent, or an injectable analgesic or intravenous fluid. Thus the percentage of patients with an injection prescribed was $100 \%$ in our study.

The antibacterial agents were given for average duration of 3 to 5 days. In our study we found that out of 19 different drugs 10 drugs were prescribed by generic name $(52.63 \%)$ and remaining 9 drugs were prescribed by brand name $(47.3 \%)$ (Figure 3 ).

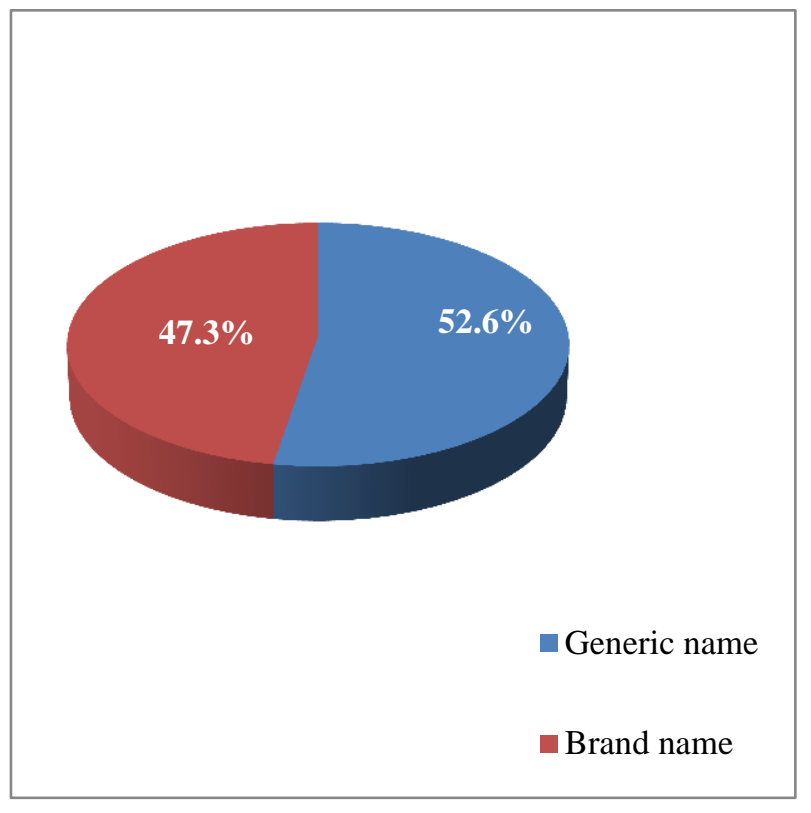

Figure 3: Percentage of drugs prescribed by generic name.

Out of 19 different drugs prescribed, 16 (84.21\%) were from the Essential Medicines WHO Model List (Figure 4). The post-operative pain was managed with Tramadol
(96\%) with average duration of 3-5 days, followed by pentazocin (87\%) and diclofenac sodium (4\%) (Figure 5).

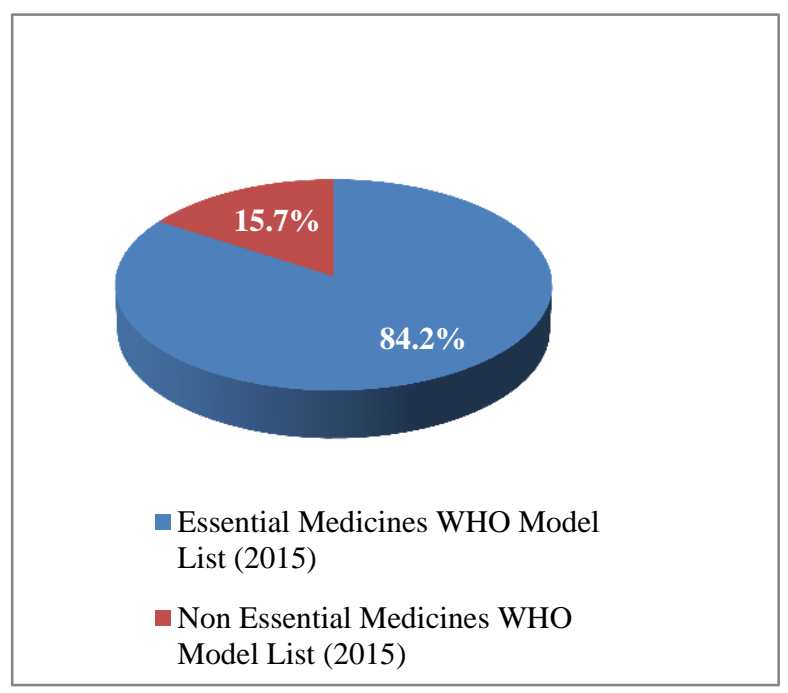

Figure 4: Prescription from essential medicine list.

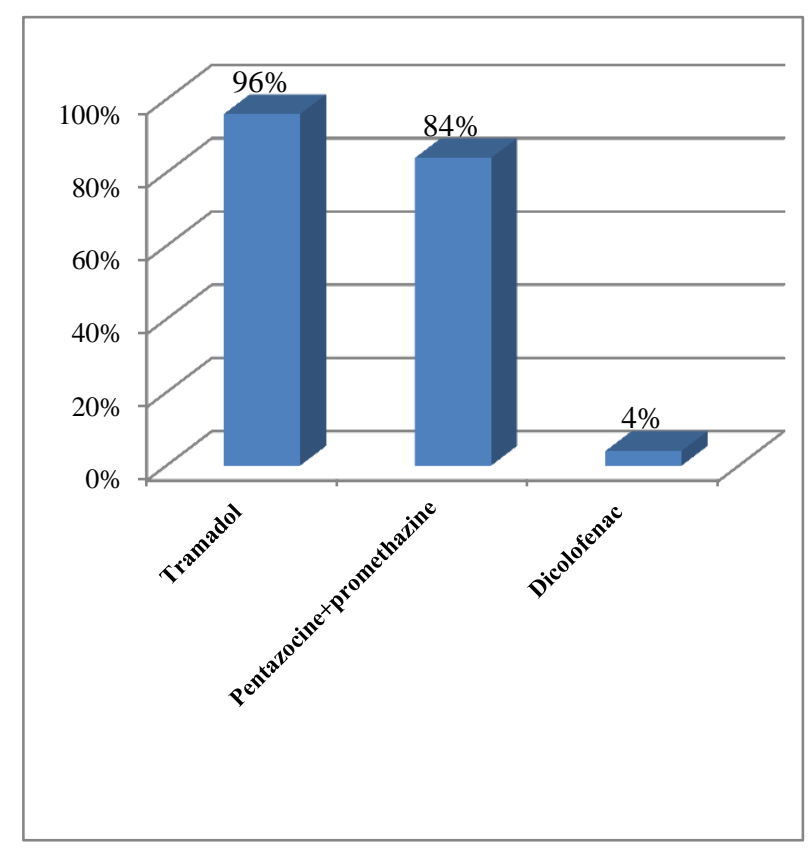

Figure 5: Percentage of analgesic usage.

\section{DISCUSSION}

Rational use of antimicrobial is extremely important as injudicious use can adversely affect the patient, cause emergence of antimicrobial resistance and increase the cost. $^{10-11}$

The use of antibacterial prophylaxis has been shown to prevent post-surgical wound infection. When employed rationally, significant reduction in the mortality and morbidity and saving in resources can be achieved. ${ }^{12-13}$ 
The purpose of antibacterial prophylaxis is to prevent postoperative infections, which are the primary cause of morbidity and mortality in patients undergoing surgery today. Aseptic techniques alone could decrease, but do not completely eliminate bacterial contamination of the surgical field. Therefore, the need for antibacterial agent to supplement aseptic technique becomes more widely accepted. $^{14}$

In present study, surgery for LSCS was very common and accounted for a total of 546 patients which was $93.7 \%$ which is higher than the findings of Shah BK et al which was $45.5 \% .^{15}$ This difference is because, in our study most of the patients were from low socioeconomic status and rural area. Most of the cases were of emergency LSCS $(56.5 \%)$, because trial labour was tried before taking any patient for surgery, unless there was an absolute indication.

In our study major indication for emergency LSCS was oligohydramnios (24.9\%), followed by history of previous LSCS (23.8\%) and fetal distress (13.3\%).

The average number of drugs prescribed per patient was 9.8 with range of 5-19 which was lesser to findings of Agarwal JM et al (10.5) and Gyawali S et al (10.6). ${ }^{2,16}$

Most commonly used antibiotics in our study were Metronidazole (100\%), Cefotaxime (96\%), Piperacillin plus Tazobactam $(3.6 \%)$, ceftriaxone $(0.3 \%)$. Study of antimicrobial preference by Shah BK and Shah VN showed that Ciprofoxacin was maximally used $(60.90 \%)$ followed by ampicillin (54.54\%) and metronidazole $(39.69 \%)$.

This difference may be due to difference in the availability of drugs in different regions. In the study conducted by Heethal $\mathrm{J}$ et al most commonly used antibiotic combination was Cefotaxime plus metronidazole $(35 \%)$, followed by ceftriaxone $(25.3 \%)$ and ampicillin $(17.2 \%){ }^{17}$

The current antimicrobial preference data provides that Cefotaxime was the most commonly given to the obstetrics and gynaecological post-operative patients to minimize the surgical site infections which has also been shown different similar studies.

To prevent injection-associated infections, injection use needs to decrease and injection safety must be achieved. Several interventions were conducted world-wide to decrease injection overuse and/or to achieve safer practice. Some of them were very successful. Better communication between prescriber and patients and managerial approaches (i.e. restricting access to selected unnecessary and dangerous injectable drugs) can reduce overuse. $^{18,19}$

In our study all the post-operative patients were given injection $(100 \%)$ which was comparable to findings of
Agrawal et al (88.13\%) and higher to findings of Gyawali $\mathrm{S}$ et al $(57.04 \%))^{2,16}$

Pain is an unpleasant sensation occurring in varying degrees of severity as a consequence of injury, disease, or emotional disorder. Poor pain control is unethical, clinically unsound and economically wasteful.

Acute painful disorders are treated instantly; on the other hand severe post-operative pain and severe visceral pain are under diagnosed and under treated. Successful postoperative pain control was achieved by efficient use of health resources and patient's satisfaction. Large varieties of analgesics are available in the market which may lead to the problem of irrational prescription. ${ }^{20-22}$

The present study shows that Tramadol was the most frequently used opioid analgesic by intravenous route followed by pentazocine and diclofenac which was $96 \%$, $84 \%$ and $4 \%$ respectively. Kolawole IK et al showed that Pentazocin was the most commonly used analgesic followed by tramadol which was $86.4 \%$ and $13.6 \%$ respectively. ${ }^{23}$

Like most part of the world opioid analgesic is the mainstay of post-operative pain control in our hospital. However potent opioids like morphine and pethidine which have been found useful and effective for pain control following major surgical procedure were not used in our hospital because of non-availability of these drugs.

As prescribing by generic name will help for rational use of drugs with regard to cost, safety and efficacy by permitting the identification of the products by its scientific names, we wanted to analyse this parameter also.

In our study we found that out of 19 different drugs 10 drugs were prescribed by generic name (52.6\%) and remaining 9 drugs were prescribed by brand name $(47.3 \%)$ which was similar to findings of Bhansali NB et al $(48.7 \%) .{ }^{9}$ In study done by Kumarasingam $\mathrm{T}$ et al it was found that percentage of drugs prescribed by generic name was $39 \%$ which was lesser than the findings of our study. $^{24}$

Essential drugs are those that satisfy the health care needs of the majority of the population; they should therefore be available at all times in adequate amounts and in appropriate dosage forms and at a price that individuals and the community can afford.

This concept is intended to be flexible and adaptable to many different situations; exactly which drugs are regarded as essential remains a national responsibility. ${ }^{25}$ Out of 19 different drugs prescribed, 16 (84.2\%) were from the Essential Medicines WHO Model List which was similar to other studies like Agrawal et al (85.1\%) and Falguni et al $(92.8 \%))^{2,5,26}$ 


\section{CONCLUSION}

The present study provides valuable insight about the overall pattern of drug used in postoperative patients. The study is useful in decreasing the irrational prescription, which helps to decrease the morbidity and health care burden in the society.

\section{ACKNOWLEDGEMENTS}

We sincerely would like to acknowledge Dr. Alwar M.C, Dr. Jesudoss Prabhakaran and other colleagues for their support.

Funding: No funding sources

Conflict of interest: None declared

Ethical approval: The study was approved by the Institutional Ethics Committee

\section{REFERENCES}

1. Fourth Report of WHO Expert committee: The use of essential drug, WHO TRS 796, World Health Organization; 1990. [Internet] 2012. [Cited March 2013]. Available from: www.who.int/iris/bitstream/10665/39338/1/WHO_T RS_796.pdf

2. Agrawal JM, Patel NM, Vaniya HV, Trivedi HR, Balat JD. Drug utilization study in post-operative patients in obstetrics and gynaecology ward of a tertiary care teaching hospital. J Clin Exp Res. 2014;2:103-109.

3. Shewade D, Pradhan S. Auditing of prescriptions in a government teaching hospital and four retail medical stores in Pondicherry. Indian J Pharmacol 1998;30:408-10.

4. Nausheen S. Rational use of antibiotics - a quality improvement initiative in hospital setting. Pak Med Assoc. 2013;63(1):60-4.

5. Falguni. Use of antimicrobial prophylaxis for obstetric and gynaecological surgeries and sensitivity pattern of infective organisms. World journal of pharmacy and pharmaceutical sciences. 2014;3(6):1170-80.

6. Mangram AJ, Horan TC, Pearson ML, Silver LC, Jarvis WR. Guideline for prevention of surgical site infection. Centres for Disease Control and Prevention (CDC) Hospital Infection Control Practices Advisory Committee. American Journal of Infection Control. 1999;27:97-132. http://dx.doi.org/10.1016/S0196-6553(99)70088-X.

7. Classen DC, Evans RS, Pestotnik SL, Horn SD, Menlove RL, Burke JP. The timing of prophylactic administration of antibiotics and the risk of surgicalwound infection. The New England Journal of Medicine. 1992;32:281-6.

8. Shankar PR, Partha P, Dubey AK, Mishra P, Deshpande VY. Univ Med J. 2005;3(2):130-7.

9. Bhansali NB. Drug utilization study in postoperative patients in surgical ward of a tertiary hospital attached with medical college. Der Pharmacia Lettre. 2013;5(1):251-7.

10. Lim VKE, cheong YM, Suleiman AB. Pattern of antibiotic usage in hospital in Malaysia. Singapore Med J. 1993;34:525-8.

11. Mc Donald LC, Yu HT, Yin HC, Hsiung AC, Ho M. Use and abuse of surgical antibiotic prophylaxis in hospital in Taiwan. $\mathbf{J}$ Formos Med Assoc. 2001;100:5-13.

12. Kunin CM, Lipton HL, Tupasi T, Sacks T, Schecker W. Social, behavioral and practical factors affecting antibiotic use worldwide. Report of task force 4. Rev Infect Dis. 1987;9(1):S270-S85.

13. Ledger WJ, Prophylactic antibiotics in obstetrics and Gynaeocology. A current asset, a future liability? Expert Rev Anti Infect Ther. 2006;4:95764.

14. Gudiol F. Surgical antibiotic prophylaxis, tradition and change. Int J Clin Pract. 1998;95(1):398-438.

15. Shah BK, Shah VN. Antimicrobial use by Department of Obstetrics and Gynaecology of a tertiary care hospital: Analysis for rationality and other aspects. J Obstet Gynecol Ind. 2004;54(4):387-92.

16. Gyawali S, Shankar PR, Saha A, Mohan L. Study of prescription of injectable drugs and intravenous fluids to inpatients in a teaching hospital in Western Nepal. MJM. 2009;12:13-20.

17. Heethal. J. Pattern of antimicrobial use in caesarean

section in a tertiary care hospital in rural south India. Int J Pharm Biomed Res. 2010;1(2):57-61.

18. Hutin Y. Recent progress towards the safe and appropriate use of injections worldwide. WHO Essential Drug Monitor. 2005;34:6-7.

19. Zamin HT, Pitre MM, Conly JM. Development of an intravenous to oral route conversion program for antimicrobial therapy at a Canadian tertiary health care facility. Ann Pharmacother. 1997;31:564-70.

20. Tabish A, Jha RK. Prescribing Trend of Analgesics in a Tertiary Health Care Setup of Rural Vidarbha: A Critical Appraisal. RJPBCS. 2012;3:566-71.

21. Bertolini G, Minelli C. The use of analgesic drugs in postoperative patients: the neglected problem of pain control in intensive care units. An observational, prospective, multicentre study in 128 Italian intensive care units. Eur J Clin Pharmacol. 2002;58:73-7.

22. Swamy RM, Venkatesh G, Nagaraj HK. A prospective drug utilization evaluation of analgesics and pain assessment in postoperative urological patients in a Tertiary care hospital. Biomedical Research. 2010;21(4):401-5.

23. Kolawole IK. Post-operative apin management following caesarean section in university of Ilorin Teaching Hospital (UITH), Ilorin, Nigeria. WAJM. 2003;22(4):305-9.

24. Kumarasingam T. Drug utilization pattern of analgesics among postoperative patients in a tertiary care hospital. Der Pharmacia Lettre. 2014;6(3):40-6. 
25. Ninth Report of the WHO expert committee: The use of Essential Drugs. WHO TRS 895. 2000.

26. Nineteenth WHO Model List of Essential Medicines. 2015 http://www.who.int/medicines/publications/essential medicines/EML2015_8-May-15.pdf.
Cite this article as: Rajeshwari, Hanumantharaya N. Drug utilization study in postoperative patients in obstetrics and gynaecology ward of tertiary care hospital. Int J Basic Clin Pharmacol 2016;5:329-34. 